\title{
Tissue Expander Complications Do Not Preclude A Second Successful Implant Based Breast Reconstruction
}

\author{
Louis H Poppler, MD, MSCI ${ }^{1}$, Minh-Bao Mundschenk, MD ${ }^{1}$, Andrew Linkugel, MD ${ }^{1}$, Ema \\ Zubovic, MD ${ }^{1}$, Utku C Dolen, MD ${ }^{1}$, and Terence M Myckatyn, MD ${ }^{1}$ \\ ${ }^{1}$ Washington University in St. Louis School of Medicine; Division of Plastic and Reconstructive \\ Surgery; St. Louis, MO
}

\begin{abstract}
Background: Implant based breast reconstruction is the most common method of breast reconstruction in the United States but the outcomes of subsequent implant based reconstruction after a tissue expander (TE) complication are rarely studied. The purpose of this study is to determine the long term incidence of implant loss in patents with a previous TE complication.

Methods: This is a retrospective review of the long term outcomes of all patients with TE complications at a large academic medical center from 2003-2013. Patients with subsequent TE or implant complications were compared to those with no further complications to assess risk factors for additional complications, or reconstructive failure.

Results: One hundred sixty-two women were included in this study. The mean follow up was 8.3 \pm 3.1 years. Forty-eight women (30\%) went on to have a second TE or implant placed. They did not differ from women who went on to autologous reconstruction or no further reconstruction. Of these, 34 women (71\%) had no further complications, and 38 women (79\%) had a successful implant based reconstruction at final follow-up. There were no patient or surgical factors significantly associated with a second complication or implant loss.

Conclusions: Following TE complications, it is reasonable to offer women a second attempt at tissue expansion and implant placement. This study demonstrates that long term success rates are high and there are no definitive patient or surgical factors that preclude a second attempt at implant based breast reconstruction.
\end{abstract}

\section{INTRODUCTION}

Implant based breast reconstruction is the most common method of breast reconstruction in the United States. In 2016, nearly 89,000 breast reconstructions with implants were performed. ${ }^{1}$ In their meta-analysis of complication rates after breast reconstruction, Tsoi et al. found that $5.4 \%$ of tissue expander (TE) or implant reconstructions resulted in reconstructive failure, and that on average $9.4 \%$ of women have an infection, $7.4 \%$ have a hematoma or seroma, and $4.9 \%$ have skin flap necrosis. ${ }^{2}$ Two large cohort studies report overall complication rates for two stage TE/implant based reconstructions as high as 20-

Corresponding Author: Terence M. Myckatyn, MD, 1020 North Mason Road, Suite \#110, Creve Coeur, MO 63141. 
$50 \% ., 4$ Although the perioperative risk factors contributing to failure of implant-based reconstruction are widely known, the ultimate success rate of subsequent implant reconstruction in patients who experience a complication or loss of their TE remains unclear. $5-7$

In a retrospective study of 54 patients who had a TE complication and went on to implant placement, Adkison et al. suggest that patients with a TE complication are 3 times more likely to have a subsequent complication and 9 times more likely to lose their prosthesis. ${ }^{6}$ However, Spear, et al. report that 12 of $13(92 \%)$ patients had a successful reconstruction nearly two years after implant placement in-spite of having a previous TE complication ${ }^{5}$. Similarly, Halvorson, et al. showed that 8 of $9(89 \%)$ were able to keep an implant, although 2 patients developed late contracture. ${ }^{8}$ These studies are small, retrospective case series with short durations of follow-up and minimal bias analysis. ${ }^{9}$ Consequently, few recommendations exist for how best to manage or counsel a patient that experiences a complication of their TE but still desires implant-based reconstruction.

The study reviews a single center's 10-year experience with TE complications and subsequent implant-based breast reconstruction. Our aim was to determine the incidence of implant loss after TE complications and identify factors for implant-based reconstructive success or failure following complications. Secondary analyses also describe the causes of TE complications in this patient series and culture results among women with infections.

\section{METHODS}

\section{Study Sample}

Following IRB approval (201308013), data were retrospectively collected from the medical record. All patients who underwent mastectomy and breast reconstruction with TE placement from February 2003 to May 2013 at the Siteman Cancer Center in St. Louis, Missouri were retrospectively identified using the physician billing database of Washington University School of Medicine in St. Louis. Patients that had mastectomy and TE placement but did not experience a subsequent complication were then excluded from further study.

\section{Study Design}

Our primary analysis compared patients who did or did not have a complication of their permanent implant after having a complication with their TE. The primary outcome was removal of the permanent implant. Patient and surgical factors were compared between patients who did or did not have a second complication using univariate and multivariate logistic regression. Cancer, radiation therapy, and complication laterality were taken into account in all analyses as a complication associated with radiation of the right TE would not necessarily have any bearing on a left sided permanent implant complication.

As patients offered a permanent implant without autologous tissue flap were subject to surgeon selection bias, we first characterize the patients in our primary analysis with demographic analysis of all patients included in the study. We call this "patient selection analysis." For this analysis, patients were divided into three categories: autologous reconstruction (women who had any autologous flap with or without implant placement), 
implant only reconstruction (women who had an implant placed without a flap), and no further reconstruction. Patient and surgical factors were compared between groups. Finally, we perform a secondary analysis of the TE complications experienced by all women included in this study. We call this "complications analysis." This analysis is intended to further characterize the population of women in this study, allowing readers to decide if our results are generalizable to their patient population.

Patient and surgical factors considered important for analysis included patient age at the time of reconstruction, body mass index (BMI), diabetes mellitus (DM), and smoking status (i.e. never, prior, and current). Clinical and surgical information included laterality of the breast reconstruction, laterality of complications, acellular dermal matrix (ADM) use, chemotherapy, post-mastectomy radiotherapy, premature TE removal, permanent implant removal, and duration of reconstructive follow-up. When applicable, the time from mastectomy to radiotherapy, from mastectomy to delayed TE placement, and from TE placement to implant exchange were recorded. For premature explantation of the TE or implant, the time period from device placement to removal and reason for removal were noted. Infection was defined as resumption of oral antibiotics after routine postoperative administration, readmission for intravenous antibiotics and/or explantation. The decision to admit for intravenous antibiotics was based on surgeon preference that included consideration of failure to improve on oral antibiotics, fever, pitting edema of the skin, social support, and travel distance. Mastectomy skin flap necrosis was defined as full thickness skin loss requiring intervention, hematoma as bleeding requiring reoperation, seroma as fluid collection requiring drainage, and capsular contracture as a documented Baker Grade III or IV that required operative intervention with capsulectomy.

\section{Reconstructive technique}

Chemotherapy and radiation therapy was administered per the recommendations of the medical and radiation oncologists. For patients who received neoadjuvant chemotherapy, mastectomy was delayed at least 4 weeks from the last chemotherapy treatment. Patients received a single dose of prophylactic IV antibiotics within one hour prior to incision for all surgeries. At the time of initial breast reconstruction, the TE was placed beneath the pectoralis major, serratus anterior, and rectus fascia, or beneath the pectoralis major muscle and ADM. TEs were filled with a variable volume at the time of insertion and further expansion commenced 3-4 weeks after surgery in the absence of wound healing delays or infection. Tissue expansion was completed prior to radiotherapy in all cases except patients who had delayed reconstruction. At the time of TE exchange to permanent implant, capsulotomy or capsulectomy was always performed. Two drains were always placed at the time of TE placement and zero or one drain placed at implant exchange. Patients with a drain were always kept on prophylactic oral antibiotics, either cephalexin, trimethoprimsulfamethoxazole, or doxycycline, until it was removed.

\section{Statistical Analysis}

Categorical variables were compared between groups using Pearson's chi-squared, the Mann-Whitney U test, or Kruskal-Wallis H-test. One-way analysis of variance or the t-test were used to compare groups when variables were continuous and normally distributed. A 
Post-hoc Tukey correction was used when more than two groups were compared. Logistic regression models evaluated associations between patient and surgical factors and implant failure accounting for breast laterality, confounding factors such as timing of reconstruction, ADM use, and patient variables selected based on literature review. Confounders were selected based on literature review and removed from the model in a backwards step-wise manner based on significance within the model or a change of the beta for TE removal cause of more than $10 \% .{ }^{10}$ Statistical analyses were performed using SPSS 23 software (IBM, Chicago, IL, USA) with significance set at $\mathrm{p}<0.05$.

\section{RESULTS}

\section{Patient Characteristics}

951 women received 1453 TEs (502 bilateral, 449 unilateral) between 2003 and 2013. One hundred seventy-eight (19\%) women had a complication of their TE, or had their TE removed before completing reconstruction. Nine $(1 \%)$ women that requested their TEs be removed and $5(0.5 \%)$ women that had cancer progression requiring premature TE removal were excluded from analysis. Two women $(0.2 \%)$ were lost to follow-up before final reconstruction but after TE removal and excluded from analysis. The complication rate among patients decreased significantly over the study period from 37\% (95\% CI: $0.31-0.43$ ) among the first quartile to $23 \%$ (95\% CI: $0.17-0.29)$ among the final quartile $(\mathrm{p}<0.05)$.

One hundred sixty-two (17\%) women were included in this study (Figure 1). Mean followup duration among these women was $8.3 \pm 3.1$ years (range $4.0-14.0$ years). One hundred forty-eight women $(91 \%)$ had a TE complication in one breast and 14 women $(9 \%)$ had a TE complication in both breasts.

Following TE complications, 48 women (30\%) went on to have a second TE or implant placed (Figure 2), 47 women (29\%) went on to an autologous reconstruction (Figure 3), and 67 women $(41 \%)$ had no further reconstruction. Twenty-seven women $(17 \%)$ in the autologous reconstruction group had an implant along with a latissimus flap. None experienced further complications with their implant. Twenty women (12\%) had an autologous reconstruction without implant. Autologous flaps employed included pedicled latissimus dorsi, pedicled transverse rectus abdominis muscle (TRAM) flaps, muscle sparing TRAMs, deep inferior epigastric perforator (DIEP) and superficial inferior epigastric artery (SIEA) flaps.

Among the 162 women included in this study, 149 (92\%) underwent immediate TE placement and 13 women (8\%) underwent delayed TE placement. The median time to TE placement in patients with delayed placement was 122 days (IQR: 71-465, range 14-2199). Women who had delayed TE insertion were significantly more likely to have had adjuvant chemotherapy $(\mathrm{p}<0.01)$ than women with immediate TE insertion. Their other demographic characteristics, cancer details, and comorbidities did not differ significantly.

The first case of ADM use among patients included in this study occurred in 2004. After 2005, only 2 cases were performed without using ADM. Patients with ADM were more likely to smoke than those without $\mathrm{ADM}(38 \%$ v. $16 \%$, respectively; $\mathrm{p}<0.01)$ and to have a 
shorter duration of follow-up (7.1 v. 11.7 years, respectively; $p<0.01)$. There were no other significant differences in age, BMI, comorbidities, time to completion of reconstruction, or likelihood of permanent implant loss among patients with, or without ADM.

\section{Patient Selection Analysis}

Following tissue expander complications, selected patients were offered another attempt at implant-based reconstruction. No significant differences were seen between patients who went on to repeated alloplastic reconstruction, autologous reconstruction, and no further reconstruction (Table 1). However, patients offered a second attempt at implant based reconstruction were marginally less likely to have had radiation $(\mathrm{p}=0.06)$. The median time to implant placement after initial tissue expander placement was 316 days [IQR: 203-534].

\section{Permanent Implant Outcomes following Tissue Expander Infection}

Fourteen of 48 women (29\%) who had an implant placed subsequently had an implant complication requiring removal. The median time to implant removal was 48 days [IQR: $33-$ 277, range: 8-3817]. Four of these women (8\%) eventually had another implant placed without further complication; in total, 38 of 48 women (79\%) completed their reconstruction with a permanent implant. Three women (6\%) went on to have an autologous reconstruction. The remaining 7 women (15\%) underwent no further reconstruction. (Figure 4). Among women who went on to have an implant placed, age, race, BMI, diabetes mellitus (DM), smoking status, stage, radiation status, chemotherapy status, ADM use, the cause for TE removal, and cultures at time of TE removal did not make a significant difference for final success of implant reconstruction in univariate and multivariate logistic regression (See Appendix, Supplemental Digital Content 1, which shows the Univariate associations of patient and surgical variables with premature removal of a permanent implant, INSERT HYPER LINK).

The most common cause for implant removal was infection (5 patients (34\%)), followed by wound dehiscence/exposure (4 patients (29\%)). Mastectomy flap necrosis, capsular contracture, malposition, and pain each resulted in removal of implant(s) in one patient (7\% each patient). One further patient (7\%) requested implant removal without pathologic cause. In all but one case, the side of TE complication was the same as the side of the implant complication.

\section{Tissue Expander Complications}

Among the 162 women included in this study, 150 (93\%) required TE explantation. Twelve (7\%) women were placed on intravenous (IV) antibiotics for cellulitis and subsequently had their TE exchanged for an implant without needing a premature TE explantation. Seventysix (47\%) women were placed on intravenous antibiotics for cellulitis prior to having their TE explanted. The most common cause of TE explant was infection (85 women [52\%]), followed by mastectomy flap necrosis, implant exposure or wound dehiscence, implant leak, deflation or rupture, seroma, pain, hematoma, and capsular contracture (Table 2). The median time to IV antibiotics for breast cellulitis was 38 days (IQR: 25-87, range: 5-938). The median time to TE removal was 59 days (IQR: 28-145, range: 4-940). 
Fifty-eight of 85 women (68\%) required explant of their infected TE a median of 2 days (IQR: 1 - 3) after starting IV antibiotics. Fourteen women (16\%) initially responded to IV antibiotics followed by 15.5 days (IQR: $8.5-23.8$ ) of PO antibiotics but still required TE removal a median of 57 days (IQR: $25-55$, range 12-278) after beginning antibiotics. The remaining 12 women (14\%) did not require TE removal prior to implant exchange. The median duration of antibiotic treatment among women who responded to antibiotics was 4 days (IQR: 2.5 - 10.0) of IV antibiotics followed by 12 days (IQR: $1.8-18.0$ ) of PO antibiotics. Infection was the most common reason for TE removal among all women, regardless of whether they were treated with IV antibiotics and regardless of if their cellulitis responded to antibiotics.

Among the 12 women whose infections resolved on antibiotics and whose TEs did not require premature removal, 8 of $12(66 \%)$ had a successful implant-based reconstruction without further complications. Two women (17\%) had a successful autologous reconstruction. Only one woman (8\%) required subsequent removal of her implant for infection. Notably, her infection was Methicillin resistant Staphylococcus aureus (MRSA) and never fully resolved prior to implant exchange (Table 3).

Cultures from 82 patients were sent ( 81 at time of TE removal, 1 in a patient who only received IV antibiotics). Cultures in 29 patients had no growth. Methicillin sensitive Staphylococcus aureus (MSSA) was the most common bacterial isolate (32 of 82 cultures (39\%)). Pseudomonas aeruginosa was the second most common isolate (6 cultures (7\%)) (Table 4).

\section{DISCUSSION}

This study of outcomes of implant based reconstruction following a TE complication demonstrates that implant based reconstruction is still successful in most women ( 38 of 48 , $79 \%$ ). Among the subgroup of women whose infection resolved without the need for tissue expander explantation and went on to prosthetic reconstruction, eight of nine (89\%) recovered without further infectious complications. Our analysis failed to show any significant predictors of implant failure. This suggests that it is reasonable to offer a second try at alloplastic reconstruction to women who are not candidates for, or wish to avoid, autologous reconstruction

These results confirm the findings of prior studies and provide a larger cohort than any prior series. ${ }^{5,6,8}$ Unlike prior studies, our analysis also accounts for laterality, improving the accuracy of analysis. While our success rate was lower than prior series, our period of follow up was much longer (minimum follow-up of 4 years and mean follow-up of 8 years) and therefore likely catches late complications that were missed in prior studies. Moreover, unlike the works of Spear or Halvorson, ${ }^{5,8}$ our results support the prior work of Adkinson, et al. ${ }^{6}$ that suggests that patients who experience a TE complication are at three times the risk of permanent implant complication, and nine times more likely to have definitive implant loss. Our reconstructive failure rate of $21 \%$ among these women was higher than historically reported rates of $0.7-7.1 \%$ but our results make intuitive sense. ${ }^{2,11,12}$ Consequently, 
patients considering alloplastic reconstruction after TE complications should be informed of the increased risk of failure.

Our results do not support the findings of Adkinson, et al. that tobacco use and radiation therapy were associated with increased risk of complications in this population. ${ }^{6}$ These results are not exactly comparable because Adkinson, et al consider all TE patients rather than just those with complications and they do not parse out those who have had a TE, versus an implant, or versus a TE then implant complication. Moreover, the methodology of their analysis was not fully described and did not mention correcting for multiple comparisons. Therefore, we would still consider offering a second attempt at implant-based reconstruction to women who smoke or who have undergone ipsilateral radiation therapy, though we would certainly counsel them to stop smoking. Our series does not control for factors like soft tissue laxity, donor site adequacy, and patient willingness to consider an autologous flap and is therefore subject to significant bias. We routinely encourage patients with poor quality skin or severe radiation damage to have an autologous reconstruction with or without implants. Our acceptable results with a second attempt at prosthetic reconstruction, then, may be largely attributable to favorable patient selection and not generalizable to all patients with a failed prosthesis.

We no longer routinely keep our patients with drains on antibiotic prophylaxis although this practice remains common. ${ }^{13-17}$ Prophylactic antibiotics, when used, should cover methicillin sensitive Staphylococcus aureus as well as pseudomonas, the two most common isolates in this case series and two of the most common isolates in Halvorson's series. ${ }^{8}$ It should also cover methicillin resistant staphylococcus, coagulase negative staphylococcus, Streptococcus and Enterobacter. For our practice, doxycycline is a well-tolerated, inexpensive, and broadly effective antibiotic to limit these breast-implant associated infections. ${ }^{18}$

This study had limitations. The primary limitation is the retrospective case series design which precluded a comparison group and limited the granularity of some data. While this study is the largest series of its type to date, it is still fairly small (48 patients with the intervention of interest) and the likelihood of type II error (missing a true difference or association) is high. This study included multiple surgeons, making it more broadly generalizable but also introducing additional variability that may mask associations. This study also spanned 2003 - 2013, a period that saw the popularization of the use of acellular dermal matrices (ADM) in breast reconstruction. We stopped analyzing patients with index primary TE after 2013 to ensure a longer follow-up period; however, this may have limited the applicability of our results to current surgical practice. Future, prospective studies that better control for patient and surgical variables are warranted to determine if factors like smoking, radiation therapy, complication type (infection, mastectomy flap necrosis, etc.) should dissuade further attempts at breast reconstruction with an implant.

\section{CONCLUSIONS}

Following TE complications, it is reasonable to offer women a second attempt at tissue expansion and implant placement. These data suggest that long term success rates are around 
$79 \%$. No patient or surgical factors clearly demonstrated increased risk for a second complication. Despite this, good surgical technique and judgement is recommended with particular attention paid to infection prophylaxis. Women should be counseled that although the chance of success is high, the fact that they have had a complication increases their long term risk of failure by a factor of at least three. In light of this, every attempt should be made to limit patient risk factors by stopping smoking, weight loss, proper nutrition, and tight control of comorbidities.

\section{Supplementary Material}

Refer to Web version on PubMed Central for supplementary material.

\section{Acknowledgments}

Financial Disclosure Statement: Dr. Myckatyn receives grant funding, consultant, and advisory board fees from Allergan, investigator-initiated grant funding and consultant fees from LifeCell, investigator-initiated grant funding and consultant fees from RTI, and advisory board fees from Viveve. No other authors report any disclosures. No funds were received to conduct this study.

\section{References}

1. American Society of Plastic Surgeons. Plastic Surgery Statistics Reprot 2016 https:// www.plasticsurgery.org/documents/News/Statistics/2016/plastic-surgery-statistics-fullreport-2016.pdf. Accessed January 21, 2018.

2. Tsoi B, Ziolkowski NI, Thoma A, Campbell K, O'Reilly D, Goeree R. Safety of tissue expander/ implant versus autologous abdominal tissue breast reconstruction in postmastectomy breast cancer patients: a systematic review and meta-analysis. Plast Reconstr Surg 2 2014;133(2):234-249. [PubMed: 24469159]

3. Spear SL, Newman MK, Bedford MS, Schwartz KA, Cohen M, Schwartz JS. A retrospective analysis of outcomes using three common methods for immediate breast reconstruction. Plast Reconstr Surg 8 2008;122(2):340-347. [PubMed: 18626348]

4. Alderman AK, Wilkins EG, Kim HM, Lowery JC. Complications in postmastectomy breast reconstruction: two-year results of the Michigan Breast Reconstruction Outcome Study. Plast Reconstr Surg 6 2002;109(7):2265-2274. [PubMed: 12045548]

5. Spear SL, Masden D, Rao SS, Nahabedian MY. Long-term outcomes of failed prosthetic breast reconstruction. Ann Plast Surg 9 2013;71(3):286-291. [PubMed: 23676517]

6. Adkinson JM, Miller NF, Eid SM, Miles MG, Murphy RX, Jr. Tissue Expander Complications Predict Permanent Implant Complications and Failure of Breast Reconstruction. Ann Plast Surg 7 2015;75(1):24-28. [PubMed: 25003412]

7. Fischer JP, Wes AM, Tuggle CT, 3rd, Serletti JM, Wu LC. Risk analysis of early implant loss after immediate breast reconstruction: a review of 14,585 patients. J Am Coll Surg 12 2013;217(6):983990. [PubMed: 23973103]

8. Halvorson EG, Disa JJ, Mehrara BJ, Burkey BA, Pusic AL, Cordeiro PG. Outcome following removal of infected tissue expanders in breast reconstruction: a 10-year experience. Ann Plast Surg 8 2007;59(2):131-136. [PubMed: 17667404]

9. Huang J, Yu N, Long X. Tissue Expander Complications Predict Permanent Implant Complications and Failure of Breast Reconstruction. Ann Plast Surg 2 2016;76(2):259.

10. Maldonado G, Greenland S. Simulation study of confounder-selection strategies. Am J Epidemiol 121 1993;138(11):923-936. [PubMed: 8256780]

11. Santosa KB, Qi J, Kim HM, Hamill JB, Pusic AL, Wilkins EG. Effect of Patient Age on Outcomes in Breast Reconstruction: Results from a Multicenter Prospective Study. J Am Coll Surg 12 2016;223(6):745-754. [PubMed: 27806906] 
12. Butz DR, Lapin B, Yao K, et al. Advanced age is a predictor of 30-day complications after autologous but not implant-based postmastectomy breast reconstruction. Plast Reconstr Surg 2 2015;135(2):253e-261e.

13. Phillips BT, Fourman MS, Bishawi M, et al. Are Prophylactic Postoperative Antibiotics Necessary for Immediate Breast Reconstruction? Results of a Prospective Randomized Clinical Trial. J Am Coll Surg 6 2016;222(6):1116-1124. [PubMed: 27106640]

14. Edwards BL, Stukenborg GJ, Brenin DR, Schroen AT. Use of prophylactic postoperative antibiotics during surgical drain presence following mastectomy. Ann Surg Oncol 10 2014;21(10): 3249-3255. [PubMed: 25138078]

15. Wong A, Lee S, Nathan NS, et al. Postoperative Prophylactic Antibiotic Use Following Ventral Hernia Repair with Placement of Surgical Drains Reduces Postoperative Surgical Site Infection Rate. Plast Reconstr Surg 10 2015;136(4 Suppl):12-13.

16. Alderman A, Gutowski K, Ahuja A, Gray D. ASPS clinical practice guideline summary on breast reconstruction with expanders and implants. Plast Reconstr Surg 10 2014;134(4):648e-655e.

17. Phillips BT, Halvorson EG. Antibiotic Prophylaxis following Implant-Based Breast Reconstruction: What Is the Evidence? Plast Reconstr Surg 10 2016;138(4):751-757. [PubMed: 27307337]

18. Cohen JB, Carroll C, Tenenbaum MM, Myckatyn TM. Breast Implant-Associated Infections: The Role of the National Surgical Quality Improvement Program and the Local Microbiome. Plast Reconstr Surg 11 2015;136(5):921-929. [PubMed: 26505698] 


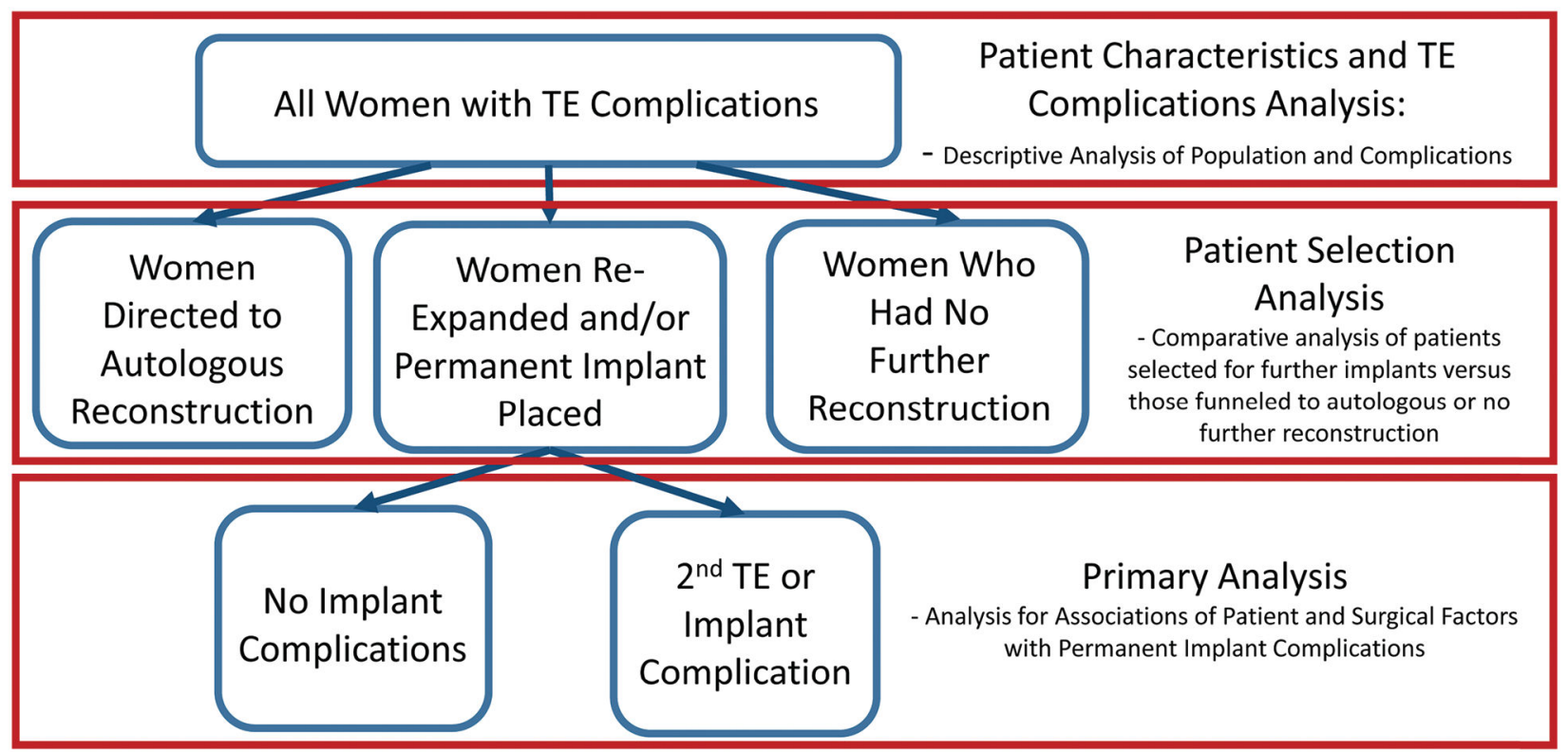

Figure 1:

Study Design and Statistical Analyses

$\mathrm{TE}=$ tissue expander 

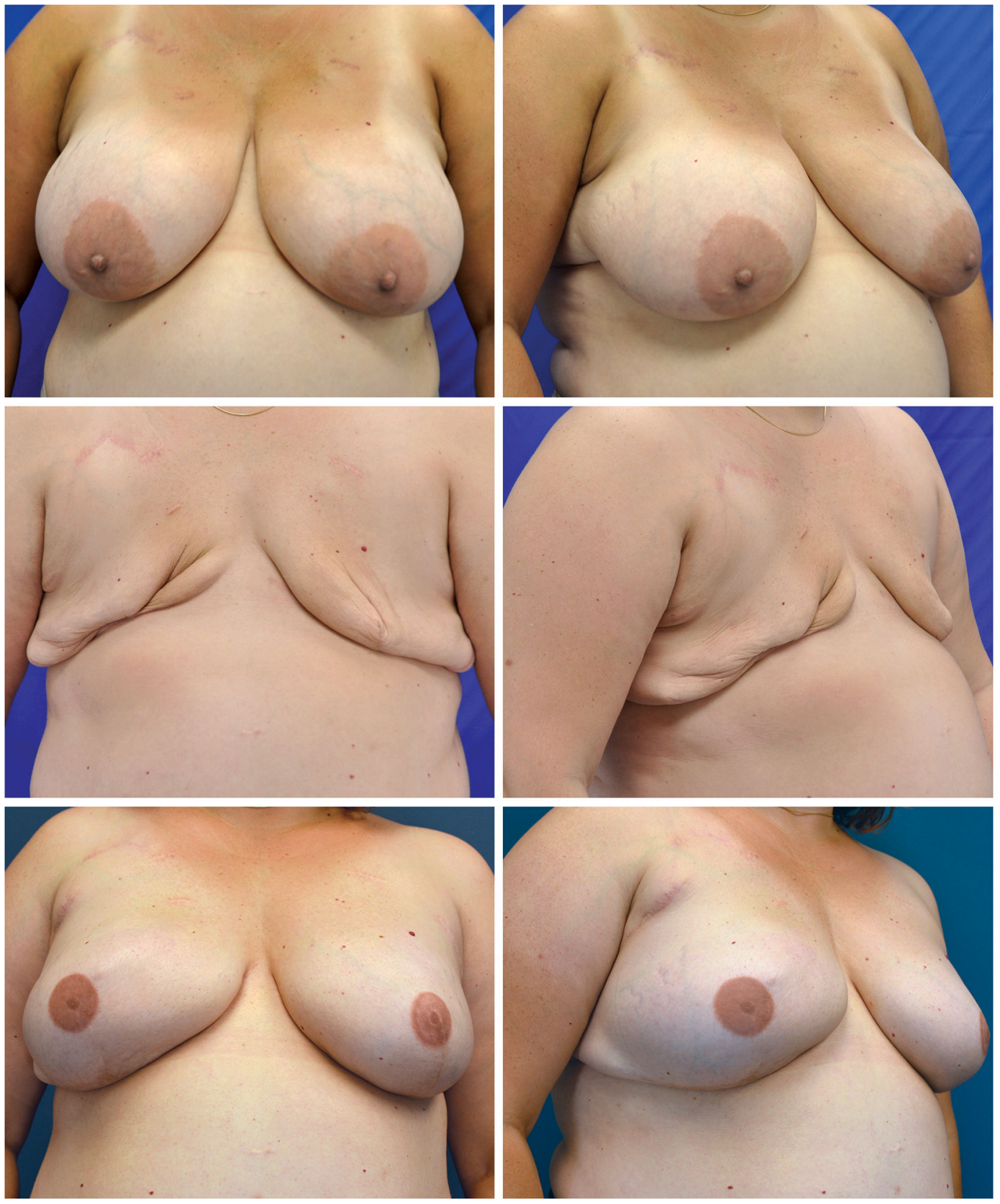

Figure 2:

Patient with bilateral failed tissue expanders successfully reconstructed with second episode of tissue expanders followed by implants. A. Preoperative frontal view prior to skin-sparing mastectomies. B. Preoperative oblique view prior to mastectomies. C. Frontal view of tissue expanders explanted on both sides following skin-sparing mastectomies, immediate subpectoral tissue expanders with acellular dermal matrix slings, and subsequent infection 67 days later. D. Oblique view of tissue expanders explanted on the both sides. E. Frontal view three years following bilateral tissue expanders followed by silicone smooth round breast implants and nipple-areola reconstructions to salvage failed tissue expander 
reconstructions. F. Oblique view three years following bilateral tissue expanders followed by implant exchanges and nipple-areola reconstructions. 

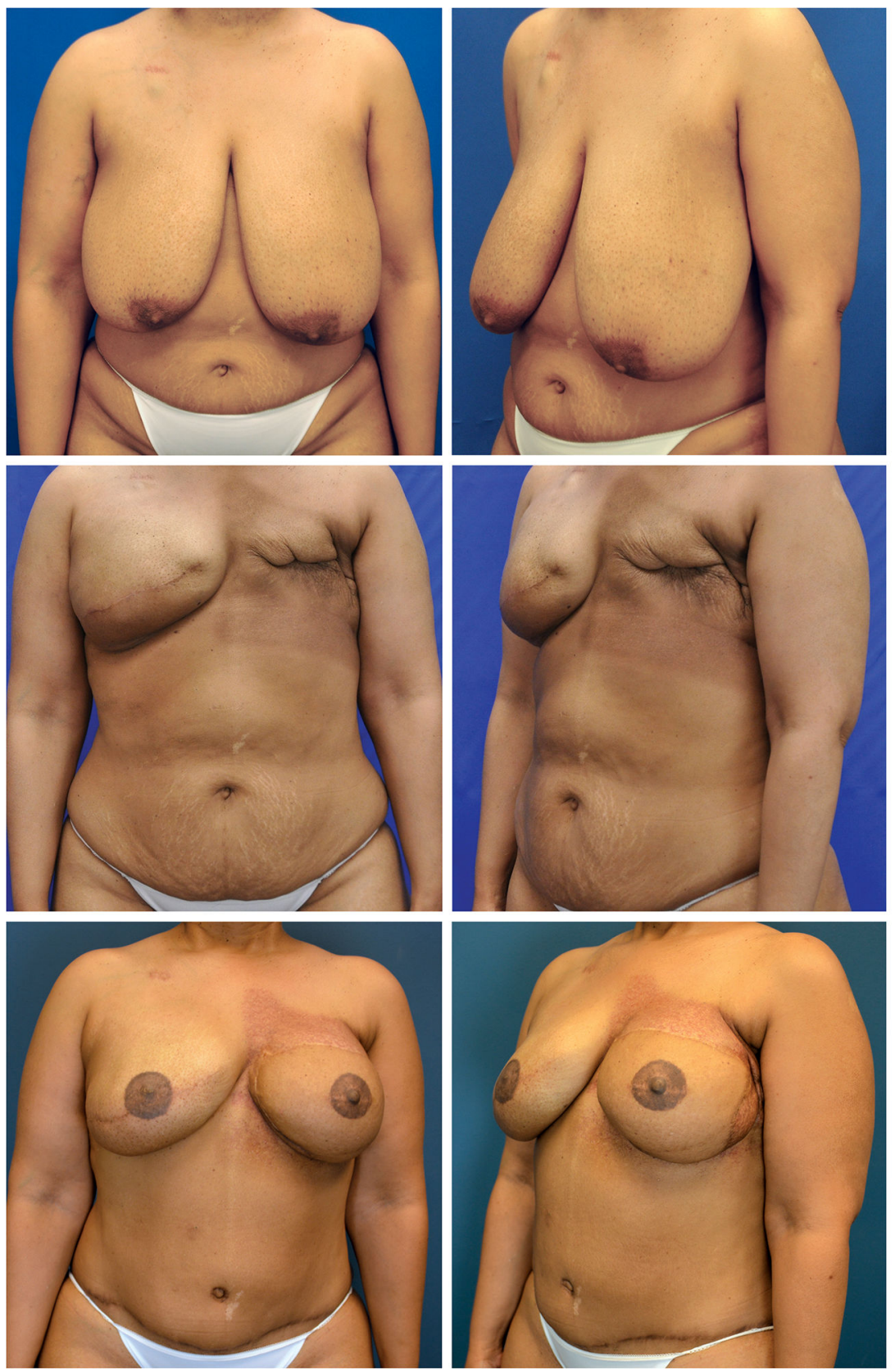

Figure 3.

Patient with failed tissue expander reconstructed with autologous flap. A. Preoperative frontal view prior to mastectomies. B. Preoperative oblique view prior to mastectomies. C. Frontal view of tissue expander explanted on the left side following radiation therapy. Right sided tissue expander remains. D. Oblique view of tissue expander explanted on the left side following radiation therapy. E. Frontal view two years following deep inferior epigastric artery perforator (DIEP) flap performed on left to salvage failed tissue expander reconstruction. Implant exchange on right and bilateral nipple-areola reconstructions also 
performed. F. Oblique view two years following DIEP flap (left), implant exchange (right) and bilateral nipple-areola reconstructions. 


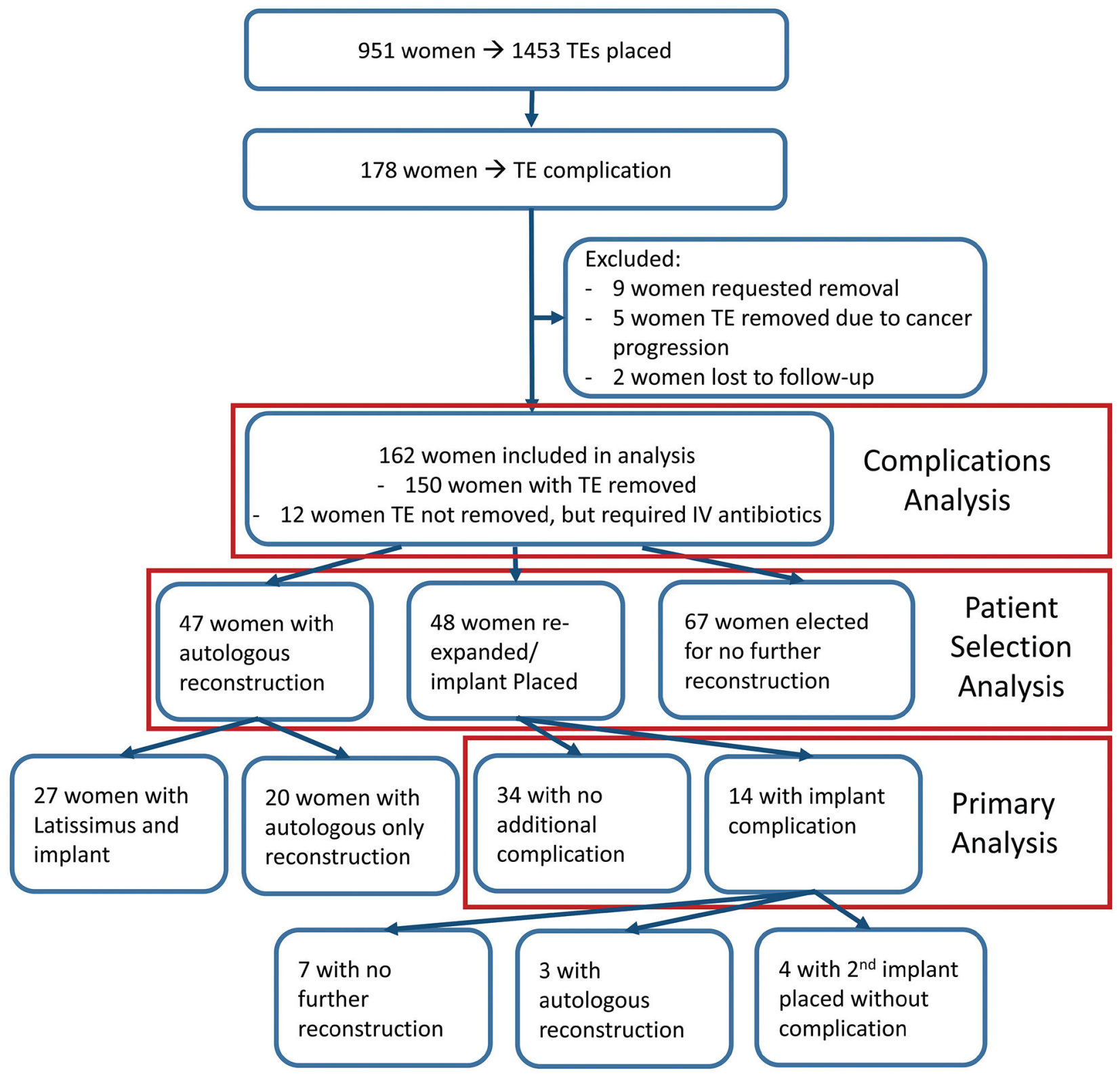

Figure 4:

Patient Inclusion and Outcomes Flowsheet

$\mathrm{TE}=$ tissue expander 
Table 1:

Comparison of Patient Characteristics by Reconstructive Pathway after TE Complication

\begin{tabular}{|c|c|c|c|c|}
\hline & $\begin{array}{l}\text { Autologous Reconstruction } \\
\text { n(\%), Mean } \pm \text { SD }\end{array}$ & $\begin{array}{c}\text { Implant Placed } \\
\mathbf{n}(\%), \text { Mean } \pm \text { SD }\end{array}$ & $\begin{array}{l}\text { No Reconstruction } \\
\text { n(\%), Mean } \pm \text { SD }\end{array}$ & $p$ value \\
\hline Number of Patients & $47(100 \%)$ & $48(100 \%)$ & $67(100 \%)$ & NA \\
\hline Age (Years) & $47 \pm 10$ & $50 \pm 12$ & $50 \pm 10$ & NS \\
\hline Race & $\begin{array}{l}\text { White - } 36(77 \%) \\
\text { Black - } 11(23 \%)\end{array}$ & $\begin{array}{c}46(96 \%) \\
2(4 \%)\end{array}$ & $\begin{array}{l}52(78 \%) \\
15(22 \%)\end{array}$ & NS \\
\hline Body Mass Index (BMI) & $30 \pm 6$ & $30 \pm 6$ & $31 \pm 8$ & NS \\
\hline Delayed TE Placement & $2(4 \%)$ & $3(6 \%)$ & $8(12 \%)$ & NS \\
\hline Clinical Stage & $\begin{array}{c}\text { Stage } 0-1-13(29 \%) \\
\text { Stage } 2-12(27 \%) \\
\text { Stage } 3-10(22 \%) \\
\text { Stage } 4-10(22 \%)\end{array}$ & $\begin{array}{c}20(53 \%) \\
7(18 \%) \\
2(5 \%) \\
9(24 \%)\end{array}$ & $\begin{array}{c}20(30 \%) \\
18(27 \%) \\
23(34 \%) \\
6(9 \%)\end{array}$ & NS \\
\hline Adjuvant Radiation & $\begin{array}{c}\text { None - } 20(43 \%) \\
\text { Post TE - } 26(55 \%) \\
\text { Pre TE - } 1(2 \%)\end{array}$ & $\begin{array}{l}28(74 \%) \\
10(26 \%) \\
0(0 \%)\end{array}$ & $\begin{array}{c}41(61 \%) \\
25(37 \%) \\
1(25 \%)\end{array}$ & NS \\
\hline Chemotherapy & $\begin{array}{c}\text { None - } 11(23 \%) \\
\text { NeoAdj. }-15(32 \%) \\
\text { Adjuvant - } 21(45 \%)\end{array}$ & $\begin{array}{l}14(33 \%) \\
12(29 \%) \\
16(38 \%)\end{array}$ & $\begin{array}{l}12(18 \%) \\
14(21 \%) \\
41(61 \%)\end{array}$ & NS \\
\hline Diabetes Mellitus & $4(9 \%)$ & $3(6 \%)$ & $9(13 \%)$ & NS \\
\hline Smoking Status & $\begin{array}{c}\text { Never - } 18(38 \%) \\
\text { Prior - } 13(28 \%) \\
16(34 \%)\end{array}$ & $\begin{array}{l}25(52 \%) \\
10(21 \%) \\
13(27 \%)\end{array}$ & $\begin{array}{l}26(39 \%) \\
17(25 \%) \\
24(36 \%)\end{array}$ & NS \\
\hline Acellular Dermal Matrix & $39(83 \%)$ & $38(79 \%)$ & $49(73 \%)$ & NS \\
\hline IV Antibiotics Given & $27(57 \%)$ & $19(40 \%)$ & $38(57 \%)$ & NS \\
\hline Follow-up (Years) & $8 \pm 3$ & $8 \pm 3$ & $9 \pm 3$ & NS \\
\hline
\end{tabular}

Bold text indicates significant differences. $\mathrm{TE}=$ Tissue Expander; NA = Not applicable; NS = Not Significant; NeoAdj. = Neo-Adjuvant; IV = Intravenous 
Table 2:

Causes for Tissue Expander Removal

\begin{tabular}{|l|c|c|}
\hline Cause & $\begin{array}{c}\text { Number of Patients } \\
\text { (\% of study population) }\end{array}$ & \% of all patients with TEs (n=951) \\
\hline Infection & $86(52 \%)$ & $9 \%$ \\
\hline Mastectomy flap necrosis & $19(12 \%)$ & $2 \%$ \\
\hline TE exposure or wound dehiscence & $18(11 \%)$ & $2 \%$ \\
\hline TE leak, deflation, or rupture & $18(11 \%)$ & $2 \%$ \\
\hline Seroma & $5(3 \%)$ & $0.5 \%$ \\
\hline Pain & $3(2 \%)$ & $0.3 \%$ \\
\hline Hematoma & $2(1 \%)$ & $0.2 \%$ \\
\hline Capsular contracture & $1(0.5 \%)$ & $0.1 \%$ \\
\hline Patient requested removal & 9 (Excluded) & $1 \%$ \\
\hline Cancer Progression & 5 (Excluded) & $0.5 \%$ \\
\hline
\end{tabular}

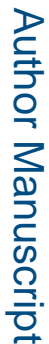


Table 3:

Patients with Salvaged Tissue Expanders after Infection

\begin{tabular}{|c|c|c|c|c|c|}
\hline Patient Number & Bacterium & Antibiotic(s) & $\begin{array}{l}\text { Duration in } \\
\text { days and } \\
\text { Route (IV vs } \\
\text { PO) }\end{array}$ & Final Outcome & Comments \\
\hline 1 & Unknown & Vancomycin & $\begin{array}{l}10 \mathrm{IV} \\
15 \mathrm{PO}\end{array}$ & No Recon & $\begin{array}{l}\text { Patient chose no further } \\
\text { reconstruction and TE was } \\
\text { removed after resolution of } \\
\text { infection }\end{array}$ \\
\hline 2 & Unknown & $\begin{array}{l}\text { Vancomycin; } \\
\text { Cefepime; } \\
\text { Clindamycin }\end{array}$ & $\begin{array}{l}5 \text { IV } \\
\text { PO Unknown }\end{array}$ & Implant & No further complications \\
\hline 3 & Unknown & $\begin{array}{l}\text { Vancomycin; } \\
\text { Piperacillin\& } \\
\text { Tazobactam; } \\
\text { Trimethoprim \& Sulfamethoxazole }\end{array}$ & $\begin{array}{l}2 \text { IV } \\
\text { PO Unknown }\end{array}$ & Implant & No further complications \\
\hline 4 & Unknown & Vancomycin; Cefepime & $14 \mathrm{IV}$ & Autologous & $\begin{array}{l}\text { Implant under latissimus } \\
\text { flap }\end{array}$ \\
\hline 5 & Pseudomonas & Gentamycin & $11 \mathrm{IV}$ & Implant & No further complications \\
\hline 6 & Unknown & $\begin{array}{l}\text { Levaquin; } \\
\text { Piperacillin\& } \\
\text { Tazobactam; } \\
\text { Amoxicillin, Clavulanate }\end{array}$ & $\begin{array}{l}4 \text { IV } \\
\text { PO Unknown }\end{array}$ & Implant & No further complications \\
\hline 7 & Unknown & $\begin{array}{l}\text { Vancomycin; } \\
\text { Trimethoprim \& Sulfamethoxazole; } \\
\text { Keflex }\end{array}$ & $\begin{array}{l}10 \mathrm{IV} \\
7 \mathrm{PO}\end{array}$ & Implant & $\begin{array}{l}\text { Seroma pocket drained at } \\
\text { time of first infection. Had } \\
\text { two episodes of cellulitis } \\
\text { managed with antibiotics } \\
\text { prior to implant exchange. } \\
\text { After exchange, no further } \\
\text { complications. }\end{array}$ \\
\hline 8 & Unknown & $\begin{array}{l}\text { Vancomycin; } \\
\text { Piperacillin\& } \\
\text { Tazobactam; } \\
\text { Trimethoprim \& Sulfamethoxazole }\end{array}$ & $\begin{array}{l}4 \mathrm{IV} \\
10 \mathrm{PO}\end{array}$ & Autologous & $\begin{array}{l}\text { Underwent bilateral DIEP } \\
\text { flaps due to poor quality } \\
\text { skin following radiation } \\
\text { therapy. }\end{array}$ \\
\hline 9 & Unknown & $\begin{array}{l}\text { Vancomycin; } \\
\text { Piperacillin\& } \\
\text { Tazobactam; } \\
\text { Trimethoprim \& Sulfamethoxazole }\end{array}$ & $\begin{array}{l}4 \mathrm{IV} \\
19 \mathrm{PO}\end{array}$ & Implant & No further complications \\
\hline 10 & MRSA & $\begin{array}{l}\text { Linezolid; } \\
\text { Trimethoprim \& Sulfamethoxazole }\end{array}$ & $\begin{array}{l}0 \mathrm{IV} \\
81 \mathrm{PO}\end{array}$ & No Recon & $\begin{array}{l}\text { Implant removed_m after } \\
\text { infection presented, } \\
\text { erythema never fully } \\
\text { resolved prior to implant } \\
\text { exchange }\end{array}$ \\
\hline 11 & Unknown & $\begin{array}{l}\text { Vancomycin; } \\
\text { Cefepime; } \\
\text { Clindamycin; } \\
\text { Ciprofloxacin }\end{array}$ & $\begin{array}{l}2 \text { IV } \\
\text { PO Unknown }\end{array}$ & Implant & No further complications \\
\hline 12 & Unknown & $\begin{array}{l}\text { Vancomycin; } \\
\text { Doxycycline }\end{array}$ & $\begin{array}{l}4 \mathrm{IV} \\
14 \mathrm{PO}\end{array}$ & Implant & $\begin{array}{l}\text { Seroma pocket opened at } \\
\text { time of infection. No } \\
\text { further complications }\end{array}$ \\
\hline
\end{tabular}


Table 4:

Tissue Expander Infection Culture Results

\begin{tabular}{|l|c|}
\hline Species & \# Of Cultures (\%) \\
\hline No Growth & $29(35 \%)$ \\
\hline Methicillin Sensitive Staphylococcus aureus & $32(39 \%)$ \\
\hline Methicillin Resistant Staphylococcus aureus & $4(5 \%)$ \\
\hline Other Gram (+) Bacteria (Streptococcus, Corynebacterium) & $2(2 \%)$ \\
\hline Pseudomonas aeruginosa & $6(7 \%)$ \\
\hline Other Gram (-) Bacteria (Enterococcus faecalis, Peptostreptococcus) & $2(2 \%)$ \\
\hline Anaerobic Species (Propionibacterium, Proteus mirabilis) & $2(2 \%)$ \\
\hline Candida Species & $1(1 \%)$ \\
\hline Multiple bacterial species & $4(5 \%)$ \\
\hline
\end{tabular}

